\title{
Genital HSV Detection among HIV-1-Infected Pregnant Women in Labor
}

\author{
Janna Patterson, ${ }^{1}$ Jane Hitti, ${ }^{2}$ Stacy Selke, ${ }^{3}$ Meei-Li Huang, ${ }^{3,4}$ D. Heather Watts, ${ }^{5}$ \\ Zane Brown, ${ }^{2}$ Lawrence Corey, ${ }^{3,6}$ and Anna Wald ${ }^{3,4,6,7}$ \\ ${ }^{1}$ Division of Neonatology, Department of Pediatrics, University of Washington, P.O. Box 356320, Seattle, WA 98195-6320, USA \\ ${ }^{2}$ Department of Obstetrics and Gynecology, University of Washington, Seattle, WA 98195-6320, USA \\ ${ }^{3}$ Department of Laboratory Medicine, University of Washington, Seattle, WA 98195-6320, USA \\ ${ }^{4}$ Vaccine and Infectious Disease Division, Fred Hutchinson Cancer Research Center, Seattle, WA 98109, USA \\ ${ }^{5}$ Pediatric, Adolescent and Maternal AIDS Branch, Eunice Kennedy Shriver National Institute of Child Health and \\ Human Development, Rockville, MD 20847, USA \\ ${ }^{6}$ Department of Medicine, University of Washington, Seattle, WA 98195-6320, USA \\ ${ }^{7}$ Department of Epidemiology, University of Washington, Seattle, WA 98195-6320, USA
}

Correspondence should be addressed to Janna Patterson, jannapat@uw.edu

Received 28 October 2010; Accepted 13 January 2011

Academic Editor: Grace John-Stewart

Copyright (C) 2011 Janna Patterson et al. This is an open access article distributed under the Creative Commons Attribution License, which permits unrestricted use, distribution, and reproduction in any medium, provided the original work is properly cited.

\begin{abstract}
Objective. To compare genital HSV shedding among HIV-positive and HIV-negative women. Methods. Women with and without known HIV infection who delivered at the University of Washington Medical Center between 1989-1996 had HSV serologies done as part of clinical care. Genital swabs from HSV-2-seropositive women were evaluated by real-time quantitative HSV DNA PCR. Results. HSV-2 seroprevalence was $71 \%$ and $30 \%$ among 75 HIV-positive and 3051 HIV-negative women, respectively, $(P<.001)$. HSV was detected at delivery in the genital tract of $30.8 \%$ of HIV-seropositive versus $9.5 \%$ of HIV-negative women $(\mathrm{RR}=3.2$, $95 \%$ CI 1.6 to $6.5, P=.001)$. The number of virion copies shed per $\mathrm{mL}$ was similar $(\log 3.54$ for HIV positive versus 3.90 for HIV negative, $P=.99)$. Conclusions. Our study demonstrated that HIV-, HSV-2-coinfected women are more likely to shed HSV at delivery.
\end{abstract}

\section{Introduction}

The rate of infant HIV infection in the USA has plummeted with the advent of routine HIV testing during pregnancy and the availability of potent antiretroviral therapy. These public health advances shift focus to prevention of other comorbid conditions in HIV-infected women and their infants.

Herpes simplex virus type 2 infections are prevalent among women and among persons with HIV infection. In resource-limited settings with high HIV prevalence such as the Central African Republic, HSV-2 antibody prevalence among HIV-infected women is 91\% [1]. Studies have reported an increased risk of HIV infection in infants born to HSV-2- and HIV-coinfected women or women who have clinical genital herpes during pregnancy $[2,3]$. The risk is likely mediated by an increase in plasma and/or mucosal HIV RNA during HSV reactivation [4] and may be abrogated by antiretroviral therapy. Less attention has been given to the potential for increased risk of neonatal herpes in infants of coinfected women. Persons with HIV and HSV-2 have increased rates of genital HSV reactivation, and, if they have advanced immunosuppression, have a higher rate of mucosal HSV shedding [1, 5-7]. Because HSV genital shedding during labor is the strongest risk factor for neonatal herpes (relative risk > 300) [8], such HIV- and HSV-2-infected women could be at increased risk for transmitting HSV to their newborns. Neonatal herpes is a devastating disease for infants with a $30 \%$ mortality rate in the case of adequately treated disseminated disease [9]. 
To assess the potential for HSV transmission to the neonate among HIV-infected women, we compared rates of HSV-2 infection and genital HSV shedding among HIVinfected and HIV-negative women.

\section{Methods}

Women with known HIV infection who delivered at the University of Washington Medical Center (UWMC), a tertiary care referral center, between 1989 and 1996 were included in the study. Additionally, women without known HIV infection delivering at UWMC between 1995-96 were included. All women were receiving comprehensive prenatal care at UWMC or affiliated clinics. During the study period, type-specific HSV serologies were included in routine prenatal care at our institution as part of a large, continuing study of HSV in pregnancy approved by the University of Washington Institutional Review Board [8]. Genital swabs were obtained in a subset of women expected to deliver vaginally as part of an ongoing study of infant exposure to HSV during birth $[8,10,11]$. Genital secretions were obtained from the labia majora and minora as well as perianal and periclitoral areas with a dacron-tipped swab. A second swab was collected from the ectocervix, endocervix, and posterior vaginal fornices during a speculum exam. HSV was cultured from the genital secretions swab, as previously reported [12]. The remaining sample was stored frozen for later testing by PCR.

HIV serologic testing was performed using a commercial enzyme-linked immunosorbent assay (Genetic Systems HIV1/HIV-2 Plus O EIA, Bio-Rad, Redmond, WA) with Western blot confirmation for samples testing positive. Type-specific HSV serostatus was determined with the University of Washington Western Blot [13]. Genital swabs were evaluated by real-time quantitative HSV DNA polymerase chain reaction (PCR) assay [14].

The prevalence of HSV-1 and HSV-2 antibodies and the median and range of log copies of HSV shed were compared among women with and without HIV infection. Categorical variables were compared using chi-square or Fisher's exact test, and continuous variables were compared using the Mann-Whitney test. Risk ratios with 95\% confidence intervals (CIs) were also calculated for the difference between these groups. A 2-sided $P$ value of .05 or less was considered statistically significant. Statistical analyses were conducted with SPSS for Windows, version 11.5.

\section{Results}

During the study interval, 75 known HIV seropositive women had a total of 85 deliveries included in this analysis. During 1995-1996, there were 3099 consecutive women admitted to Labor and Delivery who were not known to be HIV infected, and 3051 (98\%) of these women had HSV serology testing available; these were included as the comparator group. The median age was 27 (range 17, 37) for HIV-seropositive women and 29 (range 15, 49) for HIVnegative women $(P=.6)$. Among HIV-seropositive women,
$50 \%$ were white, $21 \%$ black, and 29\% other races. Among HIV seronegative women, $46 \%$ were white, $34 \%$ black, and $20 \%$ were other races. Nulliparous women comprised $31 \%$ of HIV-seropositive and 34\% of HIV-seronegative women.

Among $75 \mathrm{HIV}$-seropositive women, $71.2 \%$ had antibody to HSV-2 (28.7\% to HSV-2 only and $42.5 \%$ to HSV-2 and HSV-1), $21.9 \%$ to HSV-1 only, and $6.8 \%$ were HSV seronegative. In contrast, among $3051 \mathrm{HIV}$-seronegative women, the HSV-2 seroprevalence rate was 30.3\% (11.1\% seropositive for HSV-2 only and 19.2\% seropositive for both HSV-1 and HSV-2), while 50.6\% were HSV-1 seropositive only and $19.1 \%$ were HSV seronegative $(P<.001$ for the difference in frequency of HSV-2 antibody between HIV seropositive and HIV seronegative women).

In a subset of HSV-2 seropositive women in the study, the swab of genital secretions obtained at the time of delivery was evaluated with HSV DNA PCR swabs. Among $26 \mathrm{HIV}-$ positive, HSV-2-seropositive women who were evaluated, none had genital lesions, and all had swabs obtained for HSV from genital secretions. Among $635 \mathrm{HIV}$-negative, HSV2-seropositive women who were evaluated, 13 had lesions at delivery, and a swab for HSV was obtained from the remaining 622 for HSV detection. Vaginal deliveries were common in both groups of HSV-2-infected women without lesions as 79\% of HIV-positive women and 96\% of HIVnegative women delivered vaginally.

Genital HSV was detected in 8 (30.8\%) of $26 \mathrm{HIV}-$, HSV-2-infected women at the time of delivery. Seven of these women were HSV-2 PCR positive only, and one was HSV-2 and HSV-1 positive by PCR swab. Specifically, HSV DNA was detected in all 8 vulvar swabs, and in 4 of the $8 \mathrm{HSV}$ was also detected in the cervical swabs. Among the 622 HIV seronegative women who had swabs taken for PCR, 59 (9.5\%) women had HSV detected. Of 59 women who had HSV detected, 27 were positive both at vulva and cervix, 24 only at the vulva, and 6 only at the cervix; an additional 2 women were positive at the cervix but vulvar swabs were not available. The risk of HSV detection among HIV-seropositive women was 3.2-fold higher (95\% CI 1.6 to $6.5, P=.001$ ) than among HIV-seronegative women (Table 1). Quantitative amount of HSV in the swabs did not differ significantly between HIV-seropositive and HIVseronegative women with the median number of virion copies per $\mathrm{mL}$ of $\log 3.54$ (range $2.85,5.69$ ) for HIV-positive women versus log 3.90 (range $2.17,6.92$ ) for HIV-negative women $(P=.99$, Figure 1$)$.

\section{Discussion}

Our study showed that HSV-2- and HIV-coinfected pregnant women were more likely to shed HSV at delivery than their HIV negative counterparts. The quantitative amounts of shedding did not differ between HIV-positive and HIVnegative women, perhaps reflecting the fact that all had established HSV-2 infection. Viral shedding is the strongest risk factor for transmission of HSV from the mother to the neonate at birth [8]. While most transmissions to newborns occur from pregnant women who have recently acquired 


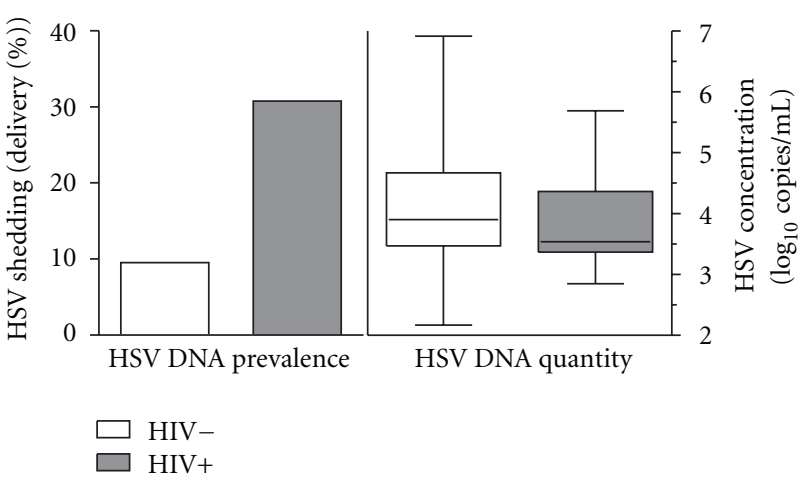

FIGURE 1: HSV shedding by PCR in HIV-positive and HIV-negative women at delivery.

genital HSV and have not developed a detectable antibody response by the time of delivery, women with established HSV-2 infection are also at risk for transmitting HSV to their neonate, but at a much lower rate [8].

Prior studies have addressed the role of HSV-2 in increasing the risk of perinatal HIV transmission [15], especially in Africa where HSV-2 infection affects most HIV-1-seropositive pregnant women [16] and highly active antiretroviral therapy is not universally used during pregnancy. Drake et al. [4] showed that genital ulcers were associated with increased plasma HIV-1 RNA and increased risk of intrapartum transmission of HIV and calculated that $14 \%$ of HIV-1 transmissions were attributable to maternal HSV-2 ulcers. The Cowan et al. study in Zimbabwe suggested that $28 \%$ of intrapartum HIV transmissions are potentially attributed to prevalent maternal HSV-2 [16]. Also concerning this cohort is the additional 17\% (29 of 193) of initially HSV-2-seronegative women who subsequently seroconverted to HSV-2 in the immediate peripartum period. This suggests that a substantial number of women acquire new HSV-2 infection peripartum, an event associated with a $30-50 \%$ risk of HSV transmission to the neonate [17]. We are aware of a single-case report of HSV transmission to the neonate from an HIV-infected woman [18]. In this case, the HSV infection was acquired at the end of pregnancy. Of note, this case was observed in a resource-rich setting, underscoring that a diagnostic workup for neonatal HSV is less likely to be routinely performed in the developing world. To our knowledge, no systematic study evaluating the incidence of neonatal HSV in resource-poor areas with high HIV prevalence has been done.

Our study was limited by a relatively small number of HIV-positive pregnant women. In addition, we focused on women who are HSV-2 seropositive, who are at lesser risk for transmitting neonatal herpes than women who acquire genital HSV in late pregnancy. Further studies of the risk of neonatal HSV among HIV-infected women should include women who are at risk for HSV acquisition in the peripartum period. Additionally, while routine heel sticks on infants born to the presumed HIV-negative women during did not reveal any unrecognized HIV infections, many of these women did not have a confirmed negative HIV test, as the
TABLE 1: HSV PCR positivity in vaginal swabs among HSV-2seropositive, HIV-positive and HIV-negative women at delivery.

\begin{tabular}{lcccc}
\hline Swab site & $\begin{array}{c}\text { HIV positive } \\
\text { women }\end{array}$ & $\begin{array}{c}\text { HIV negative } \\
\text { women }\end{array}$ & $\begin{array}{c}\text { Risk ratio, } \\
95 \% \text { CI }\end{array}$ & $P$-value \\
\hline Any site & $8 / 26(30.8 \%)$ & $59 / 622(9.5 \%)$ & $3.2(1.6,6.5)$ & .001 \\
Cervix & $4 / 25(16.0 \%)$ & $35 / 588(6.0 \%)$ & $2.7(0.9,7.3)$ & .053 \\
$\begin{array}{l}\text { Vulva } \\
\begin{array}{l}\text { Both } \\
\text { cervix and }\end{array} \\
\text { vulva }\end{array}$ & $4 / 24(33.3 \%)$ & $51 / 610(8.4 \%)$ & $4.0(2.0,8.1)$ & $<.001$ \\
\hline
\end{tabular}

study was done prior to routine HIV testing in pregnancy [19].

\section{Conclusions}

While suppressive therapy for HSV is recommended, and utilized, for prevention of genital lesions at labor and cesarean deliveries for women with a clinical history of genital herpes [20], the impact of this approach on neonatal HSV is unknown. The effect of this strategy on the high rate of HSV shedding in labor among HIV-infected, HSV2 -seropositive women has not been studied. In addition, antiviral therapy for HSV is used infrequently in resourcepoor countries. Suppressive therapy with acyclovir and valacyclovir has been shown to reduce plasma and genital HIV RNA levels by $0.25-0.50 \log$ but not to impact the risk of sexual transmission of HIV [21-23]. Ongoing studies will evaluate whether valacyclovir can reduce the risk of mother to child HIV transmission during late pregnancy, the intrapartum period, and breastfeeding.

\section{Conflict of Interests}

The authors declare no conflict of interests.

\section{Acknowledgment}

Financial support for this study provided by: NIAID PO1 AI030731 and K24 AI-071113.

\section{References}

[1] F. X. Mbopi-Keou, G. Gresenguet, P. Mayaud et al., "Interactions between herpes simplex virus type 2 and human immunodeficiency virus type 1 infection in african women: opportunities for intervention," Journal of Infectious Diseases, vol. 182, no. 4, pp. 1090-1096, 2000.

[2] G. C. John, R. W. Nduati, D. A. Mbori-Ngacha et al., "Correlates of mother-to-child human immunodeficiency virus type 1 (HIV-1) transmission: association with maternal plasma HIV-1 RNA load, genital HIV-1 DNA shedding, and breast infections," Journal of Infectious Diseases, vol. 183, no. 2, pp. 206-212, 2001.

[3] K. T. Chen, M. Segú, L. H. Lumey et al., "Genital herpes simplex virus infection and perinatal transmission of human immunodeficiency virus," Obstetrics and Gynecology, vol. 106, no. 6, pp. 1341-1348, 2005. 
[4] A. L. Drake, G. C. John-Stewart, A. Wald et al., "Herpes simplex virus type 2 and risk of intrapartum human immunodeficiency virus transmission," Obstetrics and Gynecology, vol. 109, no. 2, part 1, pp. 403-409, 2007, Erratum in Obstetrics \& Gynecology, vol. 109, no. 4, pp. 1002-1003, 2007.

[5] T. Schacker, J. Zeh, H. L. Hu, E. Hill, and L. Corey, "Frequency of symptomatic and asymptomatic herpes simplex virus type 2 reactivations among human immunodeficiency virus-infected men," Journal of Infectious Diseases, vol. 178, no. 6, pp. 16161622, 1998.

[6] M. Augenbraun, J. Feldman, K. Chirgwin et al., "Increased genital shedding of herpes simplex virus type 2 in HIVseropositive women," Annals of Internal Medicine, vol. 123, no. 11, pp. 845-847, 1995.

[7] F. Ozouaki, A. Ndjoyi-Mbiguino, J. Legoff et al., "Genital shedding of herpes simplex virus type 2 in childbearing-aged and pregnant women living in Gabon," International Journal of STD and AIDS, vol. 17, no. 2, pp. 124-127, 2006.

[8] Z. A. Brown, A. Wald, R. A. Morrow, S. Selke, J. Zeh, and L. Corey, "Effect of serologic status and cesarean delivery on transmission rates of herpes simplex virus from mother to infant," Journal of the American Medical Association, vol. 289, no. 2, pp. 203-209, 2003.

[9] D. W. Kimberlin, C. Y. Lin, R. F. Jacobs et al., "Safety and efficacy of high-dose intravenous acyclovir in the management of neonatal herpes simplex virus infections," Pediatrics, vol. 108, no. 2, pp. 230-238, 2001.

[10] Z. Brown, "Preventing herpes simplex virus transmission to the neonate," Herpes, vol. 11, supplement 3, pp. 175A-186A, 2004.

[11] D. H. Watts, Z. A. Brown, D. Money et al., "A doubleblind, randomized, placebo-controlled trial of acyclovir in late pregnancy for the reduction of herpes simplex virus shedding and cesarean delivery," American Journal of Obstetrics and Gynecology, vol. 188, no. 3, pp. 836-843, 2003.

[12] J. Hitti, D. H. Watts, S. K. Burchett et al., "Herpes simplex virus seropositivity and reactivation at delivery among pregnant women infected with human immunodeficiency virus-1," American Journal of Obstetrics and Gynecology, vol. 177, no. 2, pp. 450-454, 1997.

[13] R. L. Ashley, J. Militoni, F. Lee, A. Nahmias, and L. Corey, "Comparison of Western blot (immunoblot) and glycoprotein G-specific immunodot enzyme assay for detecting antibodies to herpes simplex virus types 1 and 2 in human sera," Journal of Clinical Microbiology, vol. 26, no. 4, pp. 662-667, 1988.

[14] K. R. Jerome, M. L. Huang, A. Wald, S. Selke, and L. Corey, "Quantitative stability of DNA after extended storage of clinical specimens as determined by real-time PCR," Journal of Clinical Microbiology, vol. 40, no. 7, pp. 2609-2611, 2002.

[15] L. J. M. Bollen, S. J. Whitehead, P. A. Mock et al., "Maternal herpes simplex virus type 2 coinfection increases the risk of perinatal HIV transmission: possibility to further decrease transmission?" AIDS, vol. 22, no. 10, pp. 1169-1176, 2008.

[16] F. M. Cowan, J. H. Humphrey, R. Ntozini, K. Mutasa, R. Morrow, and P. Iliff, "Maternal Herpes simplex virus type 2 infection, syphilis and risk of intra-partum transmission of HIV-1: results of a case control study," AIDS, vol. 22, no. 2, pp. 193-201, 2008.

[17] J. S. Sheffield, L. M. Hollier, J. B. Hill, G. S. Stuart, and G. D. Wendel, "Acyclovir prophylaxis to prevent herpes simplex virus recurrence at delivery: a systematic review," Obstetrics and Gynecology, vol. 102, no. 6, pp. 1396-1403, 2003.

[18] A. Nasoodi, S. Quah, and W. W. Dinsmore, "Neonatal herpes in herpes simplex virus type 2 and HIV-seropositive pregnant patients; the role of preventive measures in the absence of clinical disease of herpes," International Journal of STD and AIDS, vol. 18, no. 12, pp. 863-866, 2007.

[19] "U.S. Public Health Service recommendations for human immunodeficiency virus counseling and voluntary testing for pregnant women," Morbidity and Mortality Weekly Report Recommendations and Reports, vol. 44, no. RR-7, pp. 1-15, 1995.

[20] J. S. Sheffield, J. Hill, V. Laibl, L. M. Hollier, P. Sanchez, and G. D. Wendel, "Valacyclovir suppression to prevent recurrent herpes at delivery: a randomized controlled trial," Obstetrics and Gynecology, vol. 104, no. 4, p. 5s, 2005.

[21] D. Watson-Jones, H. A. Weiss, M. Rusizoka et al., "Effect of herpes simplex suppression on incidence of HIV among women in Tanzania," New England Journal of Medicine, vol. 358, no. 15, pp. 1560-1571, 2008.

[22] C. Celum, A. Wald, J. R. Lingappa et al., "Acyclovir and transmission of HIV-1 from persons infected with HIV-1 and HSV-2," New England Journal of Medicine, vol. 362, no. 5, pp. 427-439, 2010.

[23] S. Delany, N. Mlaba, T. Clayton et al., "Impact of aciclovir on genital and plasma HIV-1 RNA in HSV-2/HIV-1 coinfected women: a randomized placebo-controlled trial in South Africa," AIDS, vol. 23, no. 4, pp. 461-469, 2009. 


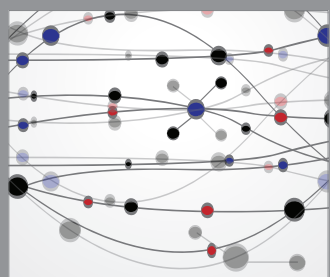

The Scientific World Journal
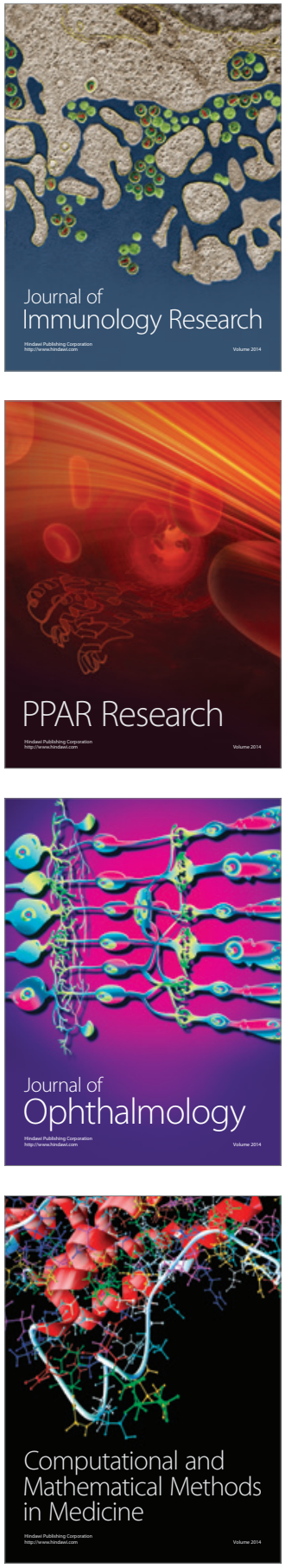

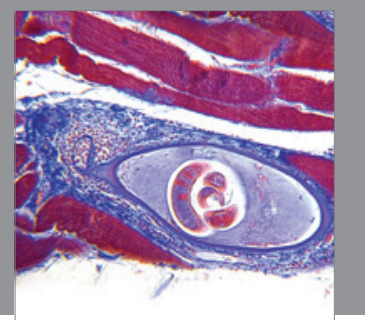

Gastroenterology

Research and Practice
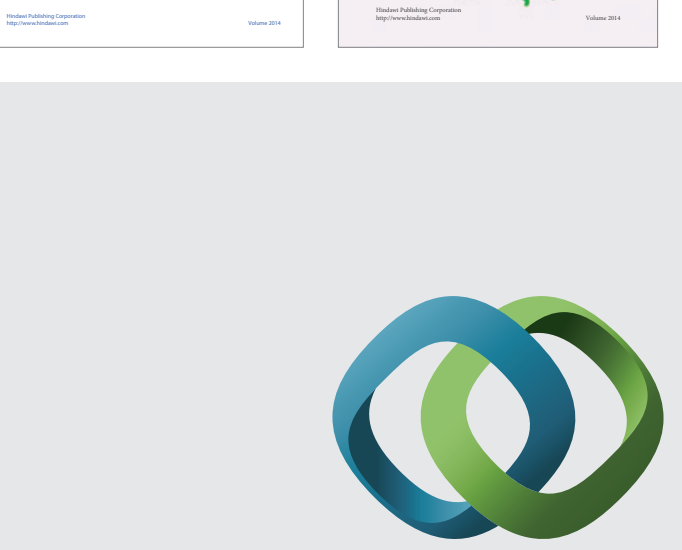

\section{Hindawi}

Submit your manuscripts at

http://www.hindawi.com
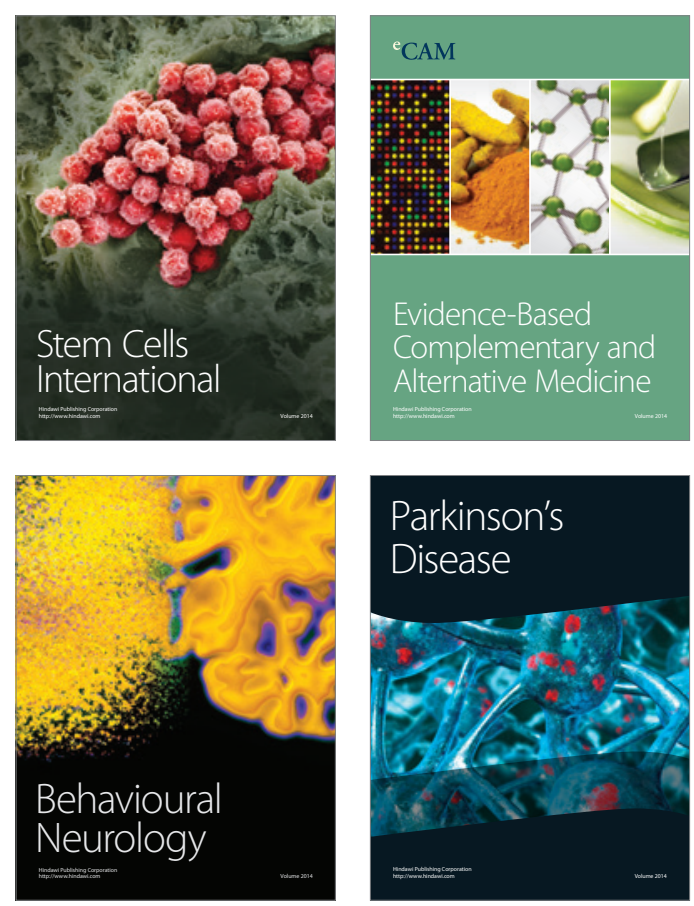

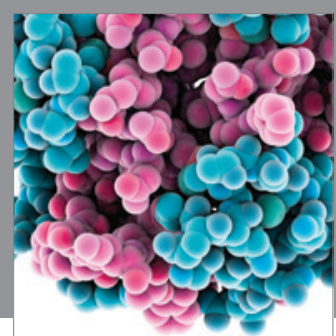

Journal of
Diabetes Research

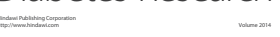

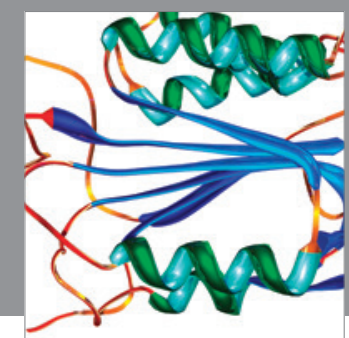

Disease Markers
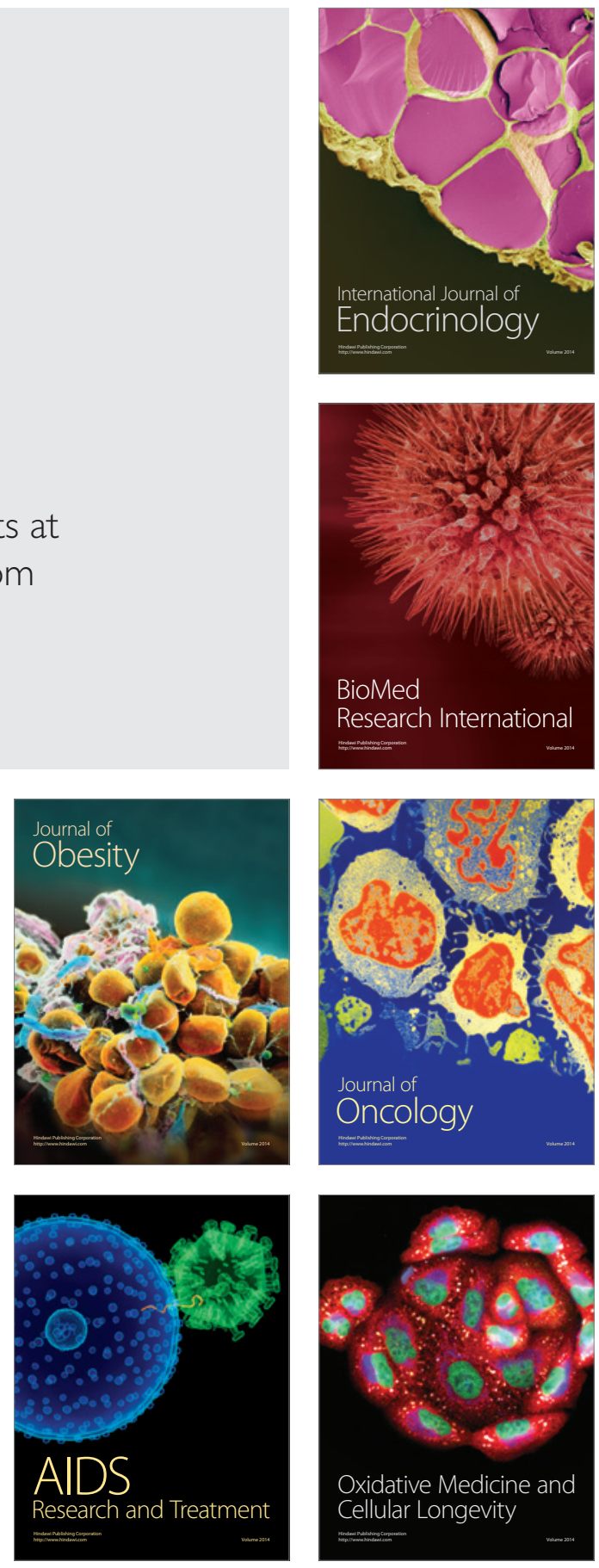